\title{
Study on the Development of Regional Water System Health from the Perspective of Systematic Thinking
}

\author{
LIU Fang ${ }^{1}$, MIAO Wang ${ }^{2,}$, LI Shuncheng $^{1}$ \\ ${ }^{1}$ School of Public Administration, Shandong Normal University, Jinan, 250014, China \\ ${ }^{2}$ School of Business Administration, QILU University of Technology, Jinan, 250353, China \\ acCorresponding Author, email: liufang7698@126.com
}

Keywords: Water System Health; Shandong Province; Regional Development; Water Resource Management; Water Ecological Civilization

\begin{abstract}
Water system health is not only an essential part and basic guarantee of water ecological civilization, but also an important support for realizing ecological civilization. From the perspective of Systematics, regional water system health is reflected by the harmonious relationship between economic social system and water system in a region. Starting from a systematic analytic thinking, this paper selects Shandong province as the research object and analyzes the achievements and problems in the development of water system health of Shandong province from multi-dimensional perspectives of water cognition, water engineering, water management, water environment, water ecology and water culture. On this basis, in consideration of the special situation of Shandong province, this paper puts forward some suggestions to improve the development of regional water system health from four aspects of engineering measures, institution measures, organization measures and public opinion guidance.
\end{abstract}

Water is the source of life, the element of production and the foundation of ecology, and the civilization degree of both water environment and water ecology plays a vital role in the construction and development of the whole ecological civilization [1]. For this research as one of the special investigation subjects of provincial government system, the author successively went to many regions like Zibo, Linyi and Hefei to conduct on-the-spot investigations from March to October of 2016, organized relevant departments to have discussions and consulted a lot of relevant literature at home and abroad. On the grounds of basic evaluation on current situation of water system health development in Shandong province, the achievements and problems during this process are analyzed and some paths to promoting the sustainable development of regional water system health are further put forward.

\section{Connotation of Regional Water System Health}

With the continuous enrichment of theoretical and practical study on the development of domestic water system health, some scholars and institutions conducted researches on the development framework of water system health. JIANG Xiaohui et al. proposed that the connotation of water system health includes four systems of water resource, water ecology, society and economy [2]. On basis of evaluation framework on ecosystem, SHI Lei constructed the evaluation index system on the water ecosystem service value in view of regional compound ecosystem, and calculated the water ecosystem service value in Qihe, Shandong province [3]. Starting from the establishment of sustainable and healthy urban water system and aiming at constructing complete water circulation system, GUI Ping et al. divided river basin unit through SWMM (Storm Water Management Model), and conducted analysis and optimal allocation on water resource so as to ensure the safe operation of water system [4]. Making cities as research objects, some scholars constructed evaluation standard system on water system health cities. For example, YU Bing et al. presented that maintaining sustainable development trend of water system is of great significance to cities' healthy development, and proposed some counter-measures and 
suggestions to maintain the sustainable development of water ecology in Dalian from two aspects of optimizing utilization mode and improving supply capacity of water resource [5]. ZHANG Jie et al. analyzed the source of contemporary water crisis, and put forward theory and implementation strategy about water environment restoration and urban water system healthy circulation [6]. From the perspectives of region and basin, some scholars made typical cities in basin and region as research objects to construct index system. For example, DING Huijun et al. constructed evaluation index system on water system healthy cities with 25 indices and six categories of water security, water management, water environment, water ecology, water landscape and water culture, and made a comprehensive evaluation on Lianhua county of Jiangxi province [7].

In summary, the regional water system health in this paper refers to that, starting from natural reality, and following the development rules of mutual support and mutual dependence among humans, society and nature (water), any demand, action and measure should be suited to the water capacity and condition, and no destruction to limited fresh water resource will be permitted, so as to make economic growth commensurate to the purified capability of regional water environment and establish sustainable water resource supply system and advanced and excellent water ecosystem.

From the angle of Systematics, regional water system health is reflected by the harmonious relationship between economic social system and water system in a region. For the end of economy and society, water security (water supply, flood protection and drainage) should be guaranteed and water resource should be allocated optimally and used rationally (water system connectivity between rivers and lakes); for the end of water system, good water environment and healthy water ecology should be kept [8][9]. The relationship between above two ends will be regulated and controlled through scientific water management and civilized water consciousness, so as to realize their harmonious coexistence (showed as Fig.1). The water system health under the condition of harmonious coexistence of social and water systems possesses following basic characters different from traditional water resource management, they are, under the situation where society and individuals rationally take certain flood risk, flood prevention security of waters of rivers and lakes should be guaranteed, especially the security of people's life and property; in consideration of strictly managing water resource like water saving, water-using security of people should be guaranteed, especially the security of person-livestock drinking water; meanwhile, for human's sustainable development, the aquatic ecosystem should be kept good as much as possible, not only keeping good water quality, but also providing basic habitats and water environment conditions for rare and endemic aquatic organisms.

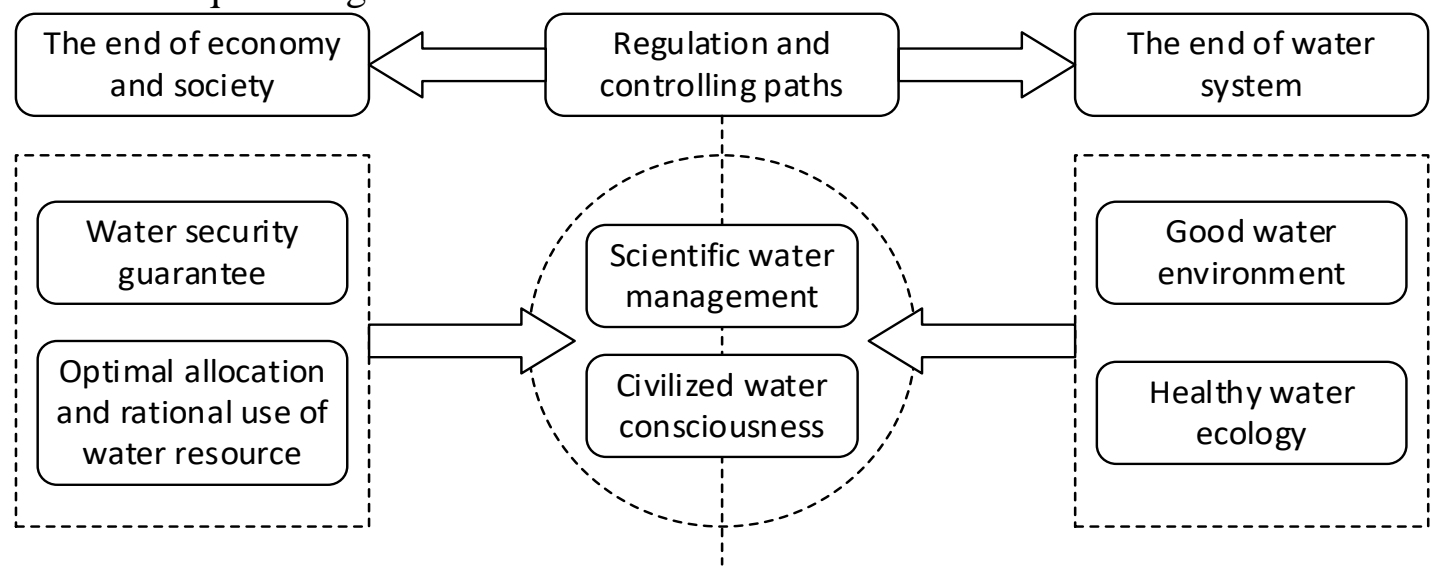

Fig.1. Mutual coordination and coexisting relationship between economic and social system and water system

\section{Current Situation of Water System Health Development in Shandong Province from the Perspective of Systematic Thinking}

(1) The Cognition of Water System Health is Continuously Deepened

Shandong province correspondingly made and improved a series of rules and policies matching the development of water system health in order to establish legal and policy systems for 
strengthening water resource protection and realizing water system health, such as Provisions on Water Consumption Control in Shandong, Implementation Opinions of People's Government of Shandong Province about Carrying out China [2012] No.3 Document and Implementing the Strictest Management System of Water Resource, The interim Measures of Shandong Province for Assessing the Strictest Water Resource Management System, The Opinion of Shandong Province about Strengthening the Treatment and Recycle of Sewage and so on. Furthermore, with the population growth, economic development and social progress of Shandong province, many restraining factors get prominent, like aggravation of the contradiction between supply and demand of water resource becoming cutoff and shrinkage of river channels, water pollution, degradation of water ecology and so on, affecting the improvement of people's living environment and life quality. The broad masses of the people and all social circles' appeal for strengthening water resource protection becomes more and more pressing. More and more problems about water resource protection are reflected through network, mass media, suggestions and proposals, which shows the cognition and recognition degrees of the whole society about the prevention and treatment of water pollution and water resource protection have been improved obviously. The awareness and concept of loving water, cherishing water and protecting water are deeply rooted in people's hearts.

(2) The Construction of Water Conservancy Projects is Increasingly Improved

With the completion of Shandong section in South-to-North Water Diversion Project (East Route) and Jiaodong Water Transfer Project as well as the successive construction of water network in cities and counties, the backbone water network framework has been basically finished and produced benefits. By now, Shandong province has constructed over 47000 surface water storage projects of various kinds with a total water storage capacity of about 22 billion $\mathrm{m}^{3}$ and dug over 9 million underground wells. The annual total water supply capacity of all kinds of water conservancy projects in Shandong province has reached 28 billion $\mathrm{m}^{3}$. Especially Weifang city we investigated this time has successively constructed 19 water system connectivity projects in recent years and newly established over 3600 water storage projects. In the city, water resource allocation project system has been formed to realize the chaining of reservoirs and rivers as well as mutual complement in drought and rainy periods. For example, the water retaining and storage project of Dawen River comprehensive development in Taian city is suited to local conditions. According to the characteristics of Dawen River, this project leads the way to driving the comprehensive usage and governance of river channels, so as to improve allocation capability of water resource and comprehensive utilization level of rainwater and flood resources of river channels, and realize the comprehensive usage of Dawen River. After implementation of the project, the total retaining and storing water surface length can reach $48.05 \mathrm{~km}$ with a water surface of 31,900 mu and total retaining and storing capacity of 63.73 million $\mathrm{m}^{3}$. A series of multi-functional water conservancy project junctions integrating flood protection, water storage, irrigation, electricity generation and tourism together, have been new-built and rebuilt.

(3) Water Resource Management Has Produced a Remarkable Effect

Per-capita water resource volume of the whole province is only $322 \mathrm{~m}^{3}$ and $263 \mathrm{~m}^{3}$ per mu, only amounting to $1 / 6$ and $1 / 7$ of national average volume. In order to break through the "water bottleneck", Shandong province put great efforts into developing water-saving economy and constructing water-saving society, realizing the increases of production and efficiency with no increase of water consumption for successive 11 years from 2003 to 2013. During this period, the economic gross of the whole province increased from over 1000 billion yuan to 5000 billion yuan and total grain yield also experienced 11-year successive increase, but compared with the total water consumption of 21.8 billion $\mathrm{m}^{3}$ in 2003, no increase happened in 2013 and the amount was lower than the controlling goal of 24.326 billion $\mathrm{m}^{3}$ (exclusive of unconventional water usage) set at the beginning of the year; the water consumption per one thousand yuan GDP decreased from 175 $\mathrm{m}^{3}$ of 2003 to $39.9 \mathrm{~m}^{3}$ of 2013, decreasing by $77.2 \%$; water consumption per one thousand yuan industrial added value decreased from $54 \mathrm{~m}^{3}$ of 2003 to $11.91 \mathrm{~m}^{3}$ of 2015 , decreasing by $77.9 \%$. The effective utilization coefficient of irrigation water reached 0.662 , ranking the fifth in the country. With $1.08 \%$ of the country's water resource, Shandong province irrigated $5.48 \%$ of the 
country's farmland, raised $7.15 \%$ of the country's population, produced $7.7 \%$ of the country's grains and supported $9.63 \%$ of the country's economic gross.

\section{(4) The Quality of Water Environment is Obviously Improved}

Shandong Provincial government successively approved some documents such as The Water Function Zoning of Shandong Province, Shallow Groundwater Over-exploitation Zoning in Plain Area of Shandong Province, Water Environment Function Zoning of Shandong Province and so on, and made Pollution Discharge Standard of Shandong River Basin stricter than national standard; in addition, Shandong province strengthened the inspection and supervision assessment of law-enforcement, enhanced the supervision of the whole process (beforehand, halfway and afterward ) of administrative approval related to water resource, and included the indices related to water resource protection into provincial committee's comprehensive evaluation index system on local scientific development. The overall quality of water environment in the whole province has got improved, and the deterioration tendency of water quality in rivers and reservoirs has initially got contained. In 2013, water quality compliance rate in water function areas of rivers and lakes in Shandong province reached $61 \%$. Since 2012, the overall quality of water environment has restored to the level of the late 1980s, the main rivers within the province has restored for the living of fish, and water quality of key water supply sources in the main cities has reached or been superior to surface water class III standard; underground water environment of the whole province has got improved to a certain extent, and the acreage of underground water over-exploitation areas has decreased from the highest level of 28,000 square $\mathrm{km}$ to the present level of 13,000 square $\mathrm{km}$.

\section{(5) The Protection of Water Ecology is Overall Promoted}

First, strengthening the construction of artificial wetland. At present, the acreage of artificial wetland in Shandong province has reached 9.5175 million mu, accounting for about 37\% of the total wetland acreage of the whole province. Only in Nansihu Basin (including Weishan Lake, Zhaoyang Lake, Dushan Lake and Nanyang Lake), 175, $000 \mathrm{mu}$ artificial wetland has been constructed, and 198,000 mu wetland has been renovated. The total acreage of soil erosion restored in the province accumulatively reached over 40,000 square $\mathrm{km}$. The abilities of water conservation and ecological remediation have been continuously improved. Second, strengthening the guidance on management and protection of drinking water sources. In 2007, Shandong province issued The List of Important Drinking Water Sources in Shandong (first batch), releasing 164 drinking water sources supplying water for above 50,000 populations. In 2008, Shandong province issued the document of Notice on Strengthening the Protection of Drinking Water Sources to Guarantee the Drinking Water Safety in Urban and Rural Areas, implementing 24 hours' inspection and patrol institution. Since July of 2015, according to the requirements of "ensuring water volume, qualifying water quality, providing complete monitoring and making institutions perfect”, the water quality of 27 key water supply sources in main cities is monitored and informed once each month. Third, strengthening forewarning management. In the light of water demand management concept, forewarning management mechanism on water volume supplied by key projects and key underground water sources should be established. After basic water level and available water volume are determined, according to the principles of keeping the priority of water supply in urban and rural areas, and coordinating water demands of production and ecology, three warning lines (yellow, orange and red) are designated, water supply forewarning management of water sources is implemented and evaluation indices of water ecology health are made.

\section{(6) Water Culture Has a Long History}

The basic thinking of constructing beautiful water ecological environment of Shandong province is not only possessing the traditional functions of flood protection and water supply, but also building a human-water harmoniously coexisting environment for people. On one hand, the construction work of water system healthy city is springing up across the province. Some brands like “Jiangbei Water City” Liaocheng, "Four Surroundings and Five Seas” Binzhou, “Ancient City of Canals" Jining, have become well-known. Eight rivers surround Linyi city. In the past, these rivers were always drying up in non-flood seasons, while now a great body of water with a total length of $88 \mathrm{~km}$ and a total acreage of 48.5 square $\mathrm{km}$ has been formed, realizing five functions of 
"water security, water economy, water culture, water ecology, water landscape" as a unit and initially constructing the framework of water system healthy city. Relying on its advantage of fountains, Jinan, known as City of Fountain, is creating modern beautiful landscape of water conservancy under the guidance of the concept “connectivity of lakes and rivers benefits people's livelihood, coordination of five waters nourishes City of Fountain", finally realizing the objective of "fountain is surging, river is unblocked, water is clean, and landscape is beautiful". On the other hand, conforming to the requirement of the times, the construction and development of water conservancy scenic spot not only guarantee the securities of flood prevention, water resource and water environment, drinking water, grains supply and economy through engineering facilities, but also create beautiful and bright landscape through great structure of water conservancy project. Especially many regions near the water naturally or artificially create fantastic waterfront landscape. So far, the province has created 57 national water conservancy scenic spots and 173 provincial water conservancy scenic spots, distributed in more than half of the counties in the province.

\section{Safeguard Measures of Water System Health Development in Shandong Province under the Perspective of Systematic Thinking}

The first is strict water abstraction management system. The project construction works like water resources appraisal, water abstraction permit approval and water and soil conservation plan approval, should be regulated, making the water resource appraisal as the prerequisite of the project's production and operation. The second is strict water utilization management system. The government should increase investment to actively promote the technology improvement and upgrade of sewage treatment plant, reconstruct overworked water supply pipeline, strengthen the unified reconstruction and management of water supply facilities for second use and strengthen centralized water supply management with self-supply wells as water resources, so as to ensure the quality security of water supply. The third is strict water discharge management system. For the water discharged into pipeline networks, departments in charge of drainage in cities should strictly examine and approve water discharge pipelines network and facilities. If the quality of discharged water reaches the standard, the departments in charge of drainage approve and issue water discharge permit license or temporary water discharge permit license; for the reclaimed water disposed by sewage treatment plant, if it's recyclable, it should be reused, and if it can't be reused, it should be discharged into water functional area after wetland purification. During the phase of water recycling, it's suggested to introduce incentives to exempt the corporations with water recycling from sewage treatment fee and water resource fee. For the corporations constructing reclaimed water reuse project, the fiscal department at all levels should offer them subsidy no higher than $10 \%$ of the total investment from sewage discharge fees, and make payment after the project passes the test and is put into operation. If the residential areas try to build experiment project of reclaimed water reuse, fiscal departments should offer them subsidy from sewage discharge fees.

\section{Conclusion}

As a brandnew concept, water system health is a system consisting of many essential factors with rich content, involving spatial structure, industrial structure, social structure, population structure, ecological structure and so on. In the process of promoting water system health development in Shandong province, it's found that there are many problems worth studying and thinking in aspects of planning, construction and management, such as normalization and individuation of water system health standards, the relationship between periodicity and chronicity, the relationship between water industry promotion and social promotion, the relationship between the construction and management of water system health project. In accordance with principles of scientificity, systematicity and timeliness, implementation plan should be gradually explored which not only shows the general level of water system health in assessed regions, but also leaves individualized constructing space, so as to continuously promote the healthy and sustainable development of regional water system. 


\section{Acknowledgement}

This paper is the phase achievement of provincial major water conservancy scientific and technology promoting program of Shandong province "Study on the Balance Sheet of Water Resource and Its Application for the Public Project Governance” (Serial Number: SDSLKY201604), humanities and social science researching program of universities and colleges in Shandong province "Innovating Study on the Multi-dimensional Policies Relating to the Poverty Alleviation Project Governance under the Perspective of Dynamic Social Network" (Serial Number: J16YF13) and philosophy and social science program of Jinan city "Studying on the Construction of Ecological City based on the Management of Environment-friendly Water Conservancy Program—Taking Jinan City as An Example” (Serial Number: JNSK16D04).

\section{References}

[1] MI Zefeng, ZENG Gang, SHANG Yongmin et al. Study on the Current Situation and Development Potential of Eco-civilization Construction of Prefecture-level City in the Yangtze River Economic Zone [J]. Resource and Environment in the Yangtze Basin, 2016, 25 (9): 1438-1447.

[2] JIANG Xiaohui, WANG Hongzhu. Change of structural characteristics and health assessment of aquatic ecosystems along the mainstream of the Yellow River[J]. Journal of Hydraulic Engineering, 2012, 43(8):991-998.

[3] SHI Lei. Assessment of Water Ecosystem Service Value and Industrial Impacts in Qihe, Shandong Province [J]. Sustainable Development, 2015, 05:74-86.

[4] GUI Ping, KONG Yanhong, LIU Guangqi et al. Study on Establishment of Sustainable Water System and Its Security Assurance [J]. City Planning Review, 2011 (s2): 66-70.

[5] YU Bing, XU Linyu. Assessment of Sustainable Development of Urban Water Ecosystem —Taking Dalian as an example [J]. Resources Science, 2014, 36 (12): 2578-2583.

[6] ZHANG Jie, LI Dong. Study on Water Environment Restoration and Urban Water System Healthy Circulation [J]. Chinese Engineering Sciences, 2012, 14 (3): 21-26.

[7] DING Huijun, LIU Jutao, YUAN Guixiang, et al. Establishment of the Evaluation Index System on the Water Ecological Civilization Construction in Lianhua County of Jiangxi Province [J]. Jiangxi Hydraulic Science and Technology, 2014, 40 (3): 165-170.

[9] LIU Fang, MIAO Wang. System Model Construction of System Elements in Water Ecological Civilization Construction [J]. China Population Resources and Environment, 2016, 26(5): 117-122. 